\title{
Un manuscrit calligraphié, daté de la Seconde Guerre mondiale
}

\section{Daniel Bornemann}

\section{(2) OpenEdition}

1 Journals

Édition électronique

URL : http://journals.openedition.org/rbnu/1431

DOI : 10.4000/rbnu.1431

ISSN : 2679-6104

\section{Éditeur}

Bibliothèque nationale et universitaire de Strasbourg

\section{Édition imprimée}

Date de publication : 1 novembre 2015

Pagination : 112-113

ISBN : 9782859230616

ISSN : 2109-2761

\section{Référence électronique}

Daniel Bornemann, «Un manuscrit calligraphié, daté de la Seconde Guerre mondiale », La Revue de la BNU [En ligne], 12 | 2015, mis en ligne le 01 mars 2020, consulté le 28 décembre 2020. URL : http:// journals.openedition.org/rbnu/1431; DOI : https://doi.org/10.4000/rbnu.1431

\section{(c) (i) (2) (2)}

La Revue de la BNU est mise à disposition selon les termes de la Licence Creative Commons Attribution - Pas d'Utilisation Commerciale - Partage dans les Mêmes Conditions 4.0 International. 


\section{NOUVELLES ACQUISITIONS PATRIMONIALES}

\section{Un manuscrit calligraphié, daté de la Seconde Guerre mondiale}

La BNU a pu acquérir un petit manuscrit, du milieu du $20^{e}$ siècle, de Claus Reinbolt (1901-1963), en langue allemande, intitulé Der getreue Hunrich et calligraphié par un ami de l'auteur. Ce récit en prose en langue allemande ne figure pas dans la liste des œuvres de l'auteur donnée dans le Nouveau dictionnaire de biographie alsacienne par Bernard Fradin. Aucun dictionnaire littéraire ne le mentionne. Est-il inédit ? Sans doute, mais il peut aussi avoir été édité dans un almanach ou une revue alsacienne.

Le manuscrit contient l'histoire d'un " baron pourfendu " au sens calvinien de l'expression, dont on découvre d'une part à Colmar, d'autre part à Reims, les deux moitiés du squelette et de l'armement. En France la partie droite, en Alsace la partie gauche. Les faits remontent à la bataille dite du Champ du Mensonge, près de Colmar, en 833 , lorsque l'empereur Louis le Pieux et ses fils se déchirent. Ayant prêté serment à toutes les parties, Hunrich, pris dans le cœur de la bataille et après s'être battu des deux côtés, avec ses dernières forces, se coupe en deux avec l'épée de Pépin. Voyant cela, l'empereur prononce une malédiction sur l'Alsace que nous proposons ainsi en traduction : " Maudit sois-tu misérable pays, toi qui offres tes meilleurs fils en pâture aux vautours et aux loups. Que le destin te déchire pour mille ans comme il a ici même déchiré le plus valeureux de tes fils ".
Le copiste et calligraphe a signé à la fin de l'œuvre par trois simples lettres, "Pat ", à la peinture bleue, en caractères romains. Il a également écrit son nom et son prénom sur la page de dédicace, en écriture Sutterlin à l'encre bleue. On retrouve cette même signature "Pat " sous les armoiries de Strasbourg qui figurent au verso de la dédicace. Il s'agit de Rudolf Patrick, qui n'est pas répertorié par les dictionnaires d'artistes alsaciens.

Le papier choisi est sans filigrane et la mise en page de l'ouvrage est régulière : le miroir est inscrit dans un carré approximatif, de 9,5 cm de largeur sur $9 \mathrm{~cm}$ de hauteur. On aperçoit encore la réglure établie par le calligraphe. Au rebours des habitudes, les marges supérieures et de fond de cahier sont plus importantes par rapport aux deux autres, dans un rapport proche du double. On compte onze lignes par page, écrites alternativement à l'encre rouge et à l'encre noire. Des pieds-de-mouche peints en bleu sont ajoutés pour marquer la fin des paragraphes. Trois lettrines bleues, orangées et or animent le texte. Le style de l'écriture est très proche de la caroline. Les lettrines appartiennent à plusieurs styles peu définis.

La reliure du volume est carrée, à dos long, couverte de percaline noire pour le dos et le tiers des plats, et rouge pour le reste des plats. Le papier utilisé par le copiste est épais, de type vélin, et a été fabriqué à la main.
Sur la page de titre, Claus Reinbolt a écrit (en allemand traduit ici) : "Aujourd'hui, le 15 mars 1944, je reçois la terrible nouvelle de la mort de mon cher jeune ami Rudolf Patrick survenue à Buon Riparo le 28 février 1944, lui qui jadis en 1942 m'offrit ce livre manuscrit. Il repose dans un cimetière militaire à Rome ". Il a ajouté, en latin : "Beati ab hoc tempore mortui ii [sic], qui Domini causa moriuntur. Requiescat in pace ". Le calligraphe et illustrateur précise, lui, au feuillet 2 qu'il a réalisé ce manuscrit pour l'auteur à l'occasion de son anniversaire, à Strasbourg, en juin 1941.

Il est difficile de savoir quel est ce "Buon Riparo ", lieu-dit ou commune d'Italie. Ce qui semble par contre vraisemblable est que le copiste ait trouvé la mort sous l'uniforme du soldat, au service du " maître " de l'Alsace d'alors.

Ce manuscrit est donc un émouvant témoignage des terribles déchirements de l'époque, dont la légende du fidèle Hunrich est une métaphore. Sa cote est MS.7.062.

\section{Daniel Bornemann}




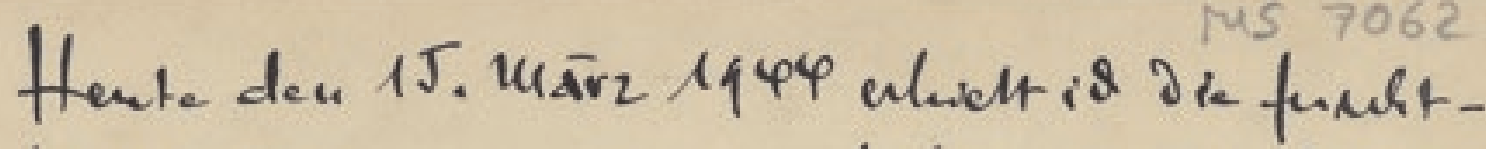

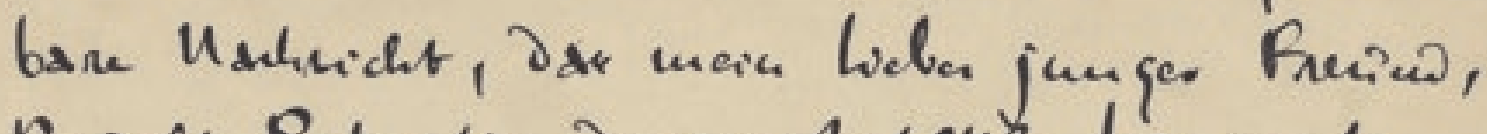
Ruodf Patriok, des ciand 1942 for mids

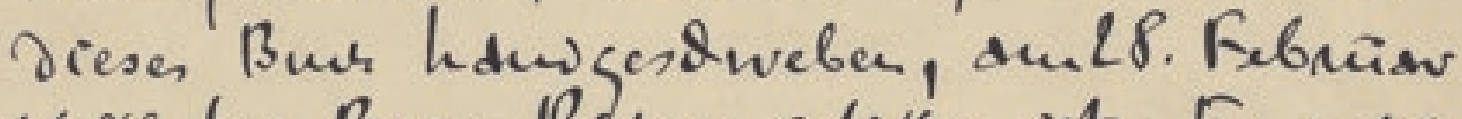
1144 bei Buon Ripaso gefallon int. En muth diff einem Hecomfievahof in Rom.

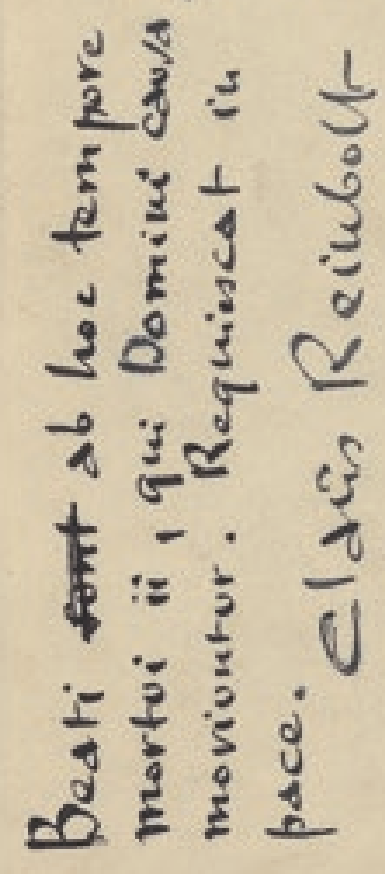

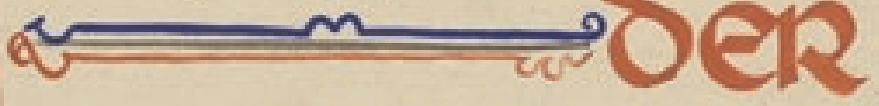

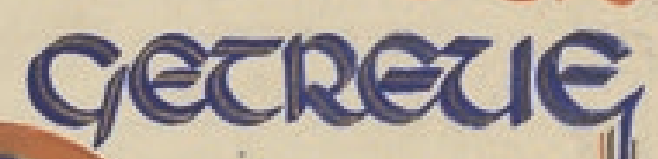

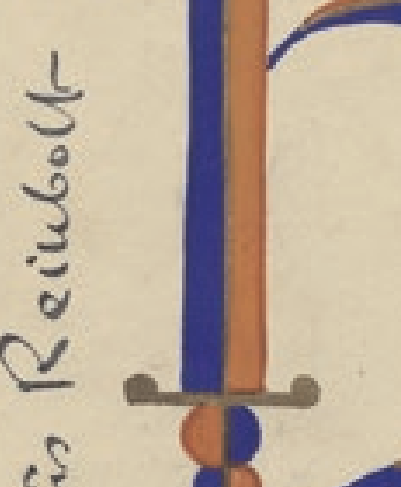
on clazus reinzoldt 